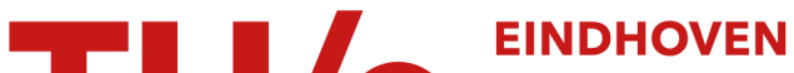 \\ UNIVERSITY OF \\ TECHNOLOGY
}

\section{Simulation and control of an automotive dry clutch}

\section{Citation for published version (APA):}

Serrarens, A. F. A., Dassen, M., \& Steinbuch, M. (2004). Simulation and control of an automotive dry clutch. In Proceedings of the 2004 American control conference, ACC : June 30 - July 2, 2004, Boston, Massachusetts (pp. 4078-4083). Institute of Electrical and Electronics Engineers.

Document status and date:

Published: 01/01/2004

\section{Document Version:}

Accepted manuscript including changes made at the peer-review stage

\section{Please check the document version of this publication:}

- A submitted manuscript is the version of the article upon submission and before peer-review. There can be important differences between the submitted version and the official published version of record. People interested in the research are advised to contact the author for the final version of the publication, or visit the $\mathrm{DOI}$ to the publisher's website.

- The final author version and the galley proof are versions of the publication after peer review.

- The final published version features the final layout of the paper including the volume, issue and page numbers.

Link to publication

\section{General rights}

Copyright and moral rights for the publications made accessible in the public portal are retained by the authors and/or other copyright owners and it is a condition of accessing publications that users recognise and abide by the legal requirements associated with these rights.

- Users may download and print one copy of any publication from the public portal for the purpose of private study or research.

- You may not further distribute the material or use it for any profit-making activity or commercial gain

- You may freely distribute the URL identifying the publication in the public portal.

If the publication is distributed under the terms of Article 25fa of the Dutch Copyright Act, indicated by the "Taverne" license above, please follow below link for the End User Agreement:

www.tue.nl/taverne

Take down policy

If you believe that this document breaches copyright please contact us at:

openaccess@tue.nl

providing details and we will investigate your claim. 


\title{
Simulation and Control of an Automotive Dry Clutch
}

\author{
Serrarens, A.F.A.; Dassen, M.; Steinbuch, M. \\ Published in: \\ Proceedings of the 2004 American Control Conference (ACC 2004)
}

Published: 01/01/2004

Document Version
Accepted manuscript including changes made at the peer-review stage

Please check the document version of this publication:

- A submitted manuscript is the author's version of the article upon submission and before peer-review. There can be important differences between the submitted version and the official published version of record. People interested in the research are advised to contact the author for the final version of the publication, or visit the DOI to the publisher's website.

- The final author version and the galley proof are versions of the publication after peer review.

- The final published version features the final layout of the paper including the volume, issue and page numbers.

Link to publication

Citation for published version (APA):

Serrarens, A. F. A., Dassen, M., \& Steinbuch, M. (2004). Simulation and Control of an Automotive Dry Clutch. In Proceedings of the 2004 American Control Conference (ACC 2004) (pp. .-). United States, Boston.

\section{General rights}

Copyright and moral rights for the publications made accessible in the public portal are retained by the authors and/or other copyright owners and it is a condition of accessing publications that users recognise and abide by the legal requirements associated with these rights.

- Users may download and print one copy of any publication from the public portal for the purpose of private study or research.

- You may not further distribute the material or use it for any profit-making activity or commercial gain

- You may freely distribute the URL identifying the publication in the public portal ?

Take down policy

If you believe that this document breaches copyright please contact us providing details, and we will remove access to the work immediately and investigate your claim. 


\section{Simulation and Control of an Automotive Dry Clutch}

\author{
Alex Serrarens \\ Drivetrain Innovations BV \\ serrarensedtinnovations.nl
}

\author{
Marc Dassen \\ Control Systems Technology \\ m.h.m.dassen@student.tue.nl
}

\author{
Maarten Steinbuch \\ Control Systems Technology \\ m.steinbuch@tue.nl
}

Technische Universiteit Eindhoven

Faculty of Mechanical Engineering

P.O. Box 513, 5600 MB Eindhoven, The Netherlands

www aes.wtb.tue.nl

\begin{abstract}
In this paper the dynamic behavior and control of an automotive dry clutch is analyzed. Thereto, a straightforward model of the clutch is embedded within a dynamic model of an automotive powertrain comprising an internal combustion engine, drivetrain and wheels moving a vehicle through tire-road adhesion. The engagement of the clutch is illustrated using the model best suited for simulation, based on work of Karnopp. These simulation results are used for conceiving a decoupling controller for the engine and clutch torque. Simulation results with the controller show significant improvement over the un-controlled case in terms of vehicle launch comfort. A modified controller is proposed that results in even more appreciated drive comfort while not deteriorating other system behavior.
\end{abstract}

\section{INTRODUCTION}

Clutches in cars, trucks and other vehicles are used to gradually engage the engine to the drivetrain while avoiding unpleasant shocks, jerks and excessive drivetrain wear. A basic clutch has two plates that can be moved together by an actuator that exerts a force on one of the two plates, see Fig. 1. This plate is called the pressure plate. The other plate- the friction plate-is connected to the crank shaft.

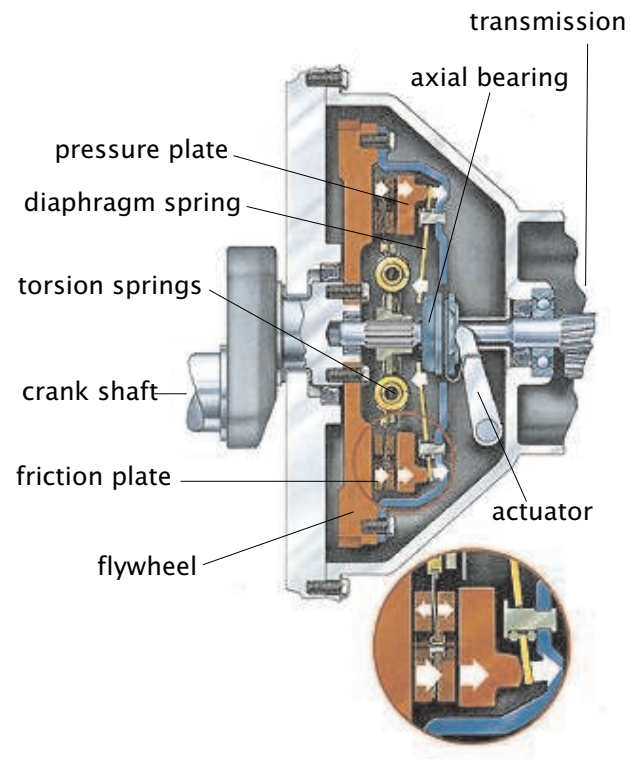

Fig. 1. Automotive Dry Clutch (LuK)
The pressure plate is connected by an axle to the gear box and the remaining part of the powertrain. As the clutch engages the plates are pushed together by the actuator. When the plates touch, torque is transmitted from the engine to the drive train. The vehicle now starts to move. After a limited amount of time the speeds of the two plates will become equal. The plates are then sticking and the engine is directly connected to the drive train. To achieve a successful engagement, the right input force has to be applied by the actuator. This can be done by the driver through a foot pedal or automatically by a programmed actuator force. One advantage of controlling a clutch automatically is of course relieving the driver of the pedal clutching task. But also an automatic clutch can be optimized further. For example wear can be predicted more accurately, because the forces acting on the clutch/brake components are known. Also fuel consumption during engagement can be minimized and the engagement time of the clutch can be shortened.

\section{A. Objectives}

The objectives of the reseach described in this paper are:

- describe the engagement of an automotive dry clutch in a dynamical model;

- design an adequate controller for smooth clutch engagement based on this model;

- simulate and analyse clutch engagement with the model;

- optimize the engagement of the clutch within a restricted time window and drive comfort;

The non-linear dynamic model of the system comprises a petrol internal combustion engine, a clutch system with torsional flexibilities, a 5 gear manual transmission, a final gear, differential, drive shafts, wheels and finally the vehicle body. For this system the launch behavior of the vehicle needs to be optimized in terms of comfort and proper engine operation. Here, the control problem is defined as:

Specify an input force, as function of a desired wheel torque, that results in a smooth, though fast engagement of the clutch. The clutch engages smoothly if the torque transmitted has a continuous and preferably non-negative derivative after the clutch sticks. 


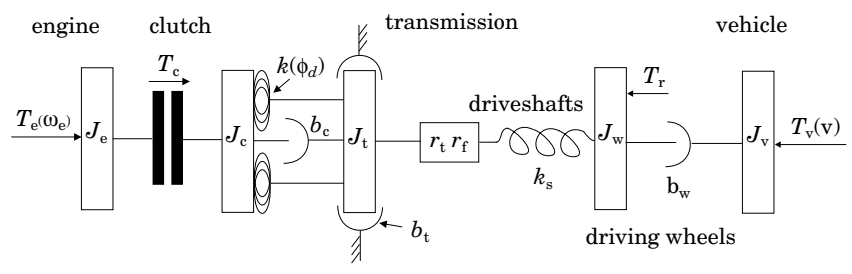

Fig. 2. Powertrain model

Our main contributions to existing work comprises an overview of different modelling structures and a modification of a known decoupling technique into a controller that enables direct control over a drive comfort variable.

\section{B. Outline}

The remainder of the paper is organized as follows. In section II, the powertrain system under consideration is presented and literature that covers either modelling or control issues of this type of system is cited. Section III presents three modelling techniques for the non-linear model. One of these models is preferred for simulation and analysis. Using the preferred model, in section IV the system is simulated using open loop commands. The results are analyzed and a decoupling control structure is proposed for the two control inputs, i.e. engine torque and clutch torque. With this decoupling controller simulations are carried out and parameters are tuned for optimal behavior. Furthermore, the modified control structure is proposed. The improvements in drive comfort are again illustrated through simulations.

\section{Passenger Car Powertrain Subsystems}

Passenger car powertrains comprise the ensemble of the internal combustion engine, launch device, transmission system, differential and the drive shafts. For modelling purposes we need to extend this definition with the wheels, tires and vehicle, see Fig. 2.

In case of (automated) manual transmissions the launch device is mostly a dry clutch, whereas for automatic and continuously variable transmission this may be either an oil immersed (wet) clutch or hydraulic torque converter. In this paper we only consider a powertrain equipped with manual transmission and automated dry clutch assembly. In the next subsections, the various elements of the powertrain are briefly discussed and basic equations for them are given. In section III, these equations are assembled in three different ways towards a total powertrain model. In this powertrain model inertias, are appropriately taken into account. Furthermore, we follow some of the modelling principles proposed in [1] and [2]. For the modelling of the clutch we exploit the work presented in [3]. Within the scope of this paper, the transmission and engine need no further detailing other than first principle modelling.

\section{A. engine}

The engine torque $T_{\mathrm{e}}$ is assumed to have infinitely fast dynamics and is only restricted by an lower and upper bound. Here, the upper bound is a quadratic function of the engine speed $\omega_{\mathrm{e}}$, whereas the lower bound equals zero. Although this represents a rather crude approximation of the real engine torque it suffices for our analysis. The engine torque is described by:

$$
0 \leq T_{\mathrm{e}} \leq T_{\max }-5 \cdot 10^{-4}\left(\omega_{T_{\max }}-\omega_{\mathrm{e}}\right),
$$

where $T_{\max }=160(\mathrm{Nm})$ is the maximum engine torque achieved at $\omega_{\mathrm{e}}=\omega_{T_{\max }}=300(\mathrm{rad} / \mathrm{s})$. Also the engine speed is bounded, i.e.

$$
\omega_{\mathrm{e}_{\min }} \leq \omega_{\mathrm{e}} \leq \omega_{\mathrm{e}_{\max }},
$$

where $\omega_{\mathrm{e}_{\min }}=100(\mathrm{rad} / \mathrm{s})$ and $\omega_{\mathrm{e}_{\max }}=600(\mathrm{rad} / \mathrm{s})$. The engine inertia $J_{\mathrm{e}}$ is driven by the engine torque and is loaded by the clutch torque $T_{\mathrm{c}}$. The equation of motion is then governed by:

$$
J_{\mathrm{e}} \dot{\omega}_{\mathrm{e}}=T_{\mathrm{e}}-T_{\mathrm{c}}
$$

\section{B. clutch}

The clutch system, shown in Fig. 1 exists of a housing, pressure plates, friction plates, a clutch disc with torsion "dampers" and a release mechanism. The clutch disk is shoved onto the transmission input shaft and is radially fixed by a splined interface. The clutch is normally closed as the diaphragm spring is pre-tensioned when assembled. The axial bearing can slide over the transmission input shaft and push against the fingers of the diaphragm spring. The direction of the release force is swapped through the lever joints and releases the pressure from the clutch disk which is then able to rotate independently from the engine.

The clutch disc is equipped with torsional dampers which are in fact coil springs that connect various segments of the clutch disc. These springs aim at maximizing the comfort level for the driver, when opening and closing the clutch. Due to the various springs in parallel and series formation a sequence of piece-wise linear stiffness regions with hysteresis emerges. Here, we use a simplified model for this complex coil spring assembly. Furthermore, the clutch plate segments introduce (mandatory) damping due to friction between them.

The clutch system is modelled as depicted in Fig. 2. The clutch disc has inertia $J_{\mathrm{c}}$ and the transmission (see also section C) has inertia $J_{\mathrm{t}}$. The torque transmitted through the clutch (both in slipping and engaged state) is indicated by $T_{\mathrm{c}}$. The speed of the clutch disc and transmission input shaft are presented by $\omega_{\mathrm{c}}$ and $\omega_{\mathrm{t}}$, respectively. We define $\varphi_{\mathrm{d}}=\varphi_{\mathrm{c}}-\varphi_{\mathrm{t}}$ and the nonlinear stiffness of the coil springs is $k\left(\varphi_{\mathrm{d}}\right)$ is simplified into the form:

$$
k\left(\varphi_{\mathrm{d}}\right)=\left\{\begin{aligned}
60[\mathrm{Nm} / \mathrm{rad}] & \text { for }-0.25 \leq \varphi_{\mathrm{d}} \leq 0.35, \\
1000[\mathrm{Nm} / \mathrm{rad}] & \text { else. }
\end{aligned}\right.
$$


1) slipping clutch: The differential equation governing the clutch dynamics can be expressed as:

$$
\begin{array}{r}
J_{\mathrm{c}} \dot{\omega}_{\mathrm{c}}=T_{\mathrm{c}}-T_{\mathrm{d}}-b_{\mathrm{c}} \cdot\left(\omega_{\mathrm{c}}-\omega_{\mathrm{t}}\right) \\
\dot{T}_{\mathrm{d}}=k\left(\varphi_{\mathrm{d}}\right) \cdot\left(\omega_{\mathrm{c}}-\omega_{\mathrm{t}}\right)
\end{array}
$$

The torque through the clutch while slipping is given by:

$$
T_{\mathrm{c}}=F_{\mathrm{n}} \mu R_{\mathrm{a}} \operatorname{sign}\left(\omega_{\mathrm{e}}-\omega_{\mathrm{c}}\right),
$$

in which $\mu$ is the friction coefficient of the clutch surface material, $R_{\mathrm{a}}$ is te active radius of the clutch plates and the normal actuation force on the clutch plate is given by $F_{\mathrm{n}}$.

2) sticking clutch: When the clutch is sticking, the engine degree of freedom is rigidly coupled to the clutch disk at the friction interface. The two differential equations of the engine and the clutch, i.e. (3) and (5) can be reduced to a single differential equation:

$$
\left(J_{\mathrm{e}}+J_{\mathrm{c}}\right) \dot{\omega}_{\mathrm{e}}=T_{\mathrm{e}}-T_{\mathrm{d}}-b_{\mathrm{c}} \cdot\left(\omega_{\mathrm{c}}-\omega_{\mathrm{t}}\right)
$$

The sticking of the clutch sustains as long as the torque transmitted through clutch $\left(T_{\mathrm{c}}\right)$ remains below the maximally transmittable torque $T_{\mathrm{c}}^{\max }$, which is given by:

$$
T_{\mathrm{c}}^{\max }=F_{\mathrm{n}} \mu_{\mathrm{stick}} R_{\mathrm{a}} \operatorname{sign}\left(\mathrm{T}_{\mathrm{c}}\right) .
$$

Here, we assume $\mu_{\text {stick }}=2 \cdot \mu$. Furthermore, the term $\operatorname{sign}\left(\mathrm{T}_{\mathrm{c}}\right)$ is non-positive in the case of vehicle (engine) braking and positive in all other cases.

\section{C. transmission \& drive shafts}

The transmission is connected with its input shaft to the flexible friction plate of the clutch. The input shaft is connected through a gear mesh to the second shaft. The second shaft is connected via the final drive to the differential. The gear ratio selected within the transmission is denoted by $r_{\mathrm{t}}$ and the final drive gear ratio by $r_{\mathrm{f}}$. The overall transmission ratio $r$ is then defined by:

$$
r=r_{\mathrm{t}} \cdot r_{\mathrm{f}}=\frac{\omega_{\mathrm{f}}}{\omega_{\mathrm{t}}}
$$

where $\omega_{\mathrm{f}}$ is the speed of the output gear of the final drive. We do not consider transmission gear shifting and all rotating transmission parts are assumed to be lumped in one inertia $J_{\mathrm{t}}$ damped by viscous damping $b_{\mathrm{t}}$. We assume straight line driving, hence the differential does not introduce a difference in speed of the left and right drive shaft. Therefore, the two drive shafts are lumped into one stiffness $k_{\mathrm{S}}$. The model of the transmission can be presented as in Fig. 2.

The equations of motion of the transmission model are given by:

$$
\begin{array}{r}
J_{\mathrm{t}} \dot{\omega}_{\mathrm{t}}=T_{\mathrm{d}}-b_{\mathrm{t}} \cdot \omega_{\mathrm{t}}-T_{\mathrm{s}} \\
\dot{T}_{\mathrm{s}}=k_{\mathrm{s}}\left(\omega_{\mathrm{f}}-\omega_{\mathrm{w}}\right)
\end{array}
$$

\section{D. wheels \& tyres}

The model structure in Fig. 2 we assume that the driving wheels and tyres are modelled as an inertia connected to the vehicle mass through a linear damper with coefficient $b_{\mathrm{w}}$. This damper forms the slipping traction interface between tyres and road. In literature, [1] a non-linear tyre traction model is proposed as a function of the tyre slip $s$ :

$$
s=\omega_{\mathrm{w}}-\frac{v_{\mathrm{v}}}{R_{\mathrm{W}}},
$$

where $\omega_{\mathrm{w}}$ is the wheel speed, $R_{\mathrm{w}}$ is the dynamic wheel radius in $(\mathrm{m})$ and $v_{\mathrm{v}}$ is the vehicle speed in $(\mathrm{m} / \mathrm{s})$. Although a non-linear tyre slip model is available in literature [1], we prefer to use the linear approximation for it at low vehicle speeds.

Finally, the tyres experience a rolling torque $T_{\mathrm{r}}$ due to deformation of the tyre surface.

The differential equation governing the wheel and tyre dynamics is then given by:

$$
J_{\mathrm{w}} \dot{\omega}_{\mathrm{w}}=T_{\mathrm{s}}-b_{\mathrm{w}} \cdot s-\alpha T_{\mathrm{r}} .
$$

The inertia $J_{\mathrm{w}}$ equals that of the two driving wheels. Furthermore, $\alpha$ is the fraction of the vehicle mass that rests upon the driving wheels.

\section{E. vehicle}

The vehicle acceleration is the result of the traction torque, air drag and the rolling resistance of the driven wheels (rear wheels for front-wheel-drive cars), i.e.

$$
J_{\mathrm{v}} \frac{\dot{v}_{\mathrm{v}}}{R_{\mathrm{w}}}=b_{\mathrm{w}} \cdot s-(1-\alpha) T_{\mathrm{r}}-\frac{1}{2} \rho A c_{\mathrm{d}} v^{2} R_{\mathrm{w}},
$$

where $J_{\mathrm{v}}=m_{\mathrm{v}} R_{\mathrm{W}}^{2}+J_{\mathrm{w}}$ is the equivalent vehicle mass summed with the inertia of the two driven wheels. Furthermore, $(1-\alpha)$ is the fraction of the vehicle mass that rests upon the driven wheels. Finally, $\rho$ is the ambient air density, $A$ is the frontal area of the vehicle, and $c_{\mathrm{d}}$ is the air resistance coefficient.

\section{ENTIRE POWERTRAin System}

The equations of motion (3), (5), (8), (11), (12), (14), and (15) can be formulated in different ways. Each formulation aims at uniting the slipping and sticking clutch into a single system description. The difficulty that arises here is the apparent change in the number of degrees of freedom. When sticking occurs the acceleration of the inertias $J_{\mathrm{e}}$ and $J_{\mathrm{c}}$ can be described by a single coordinate, viz. equation (8) instead of two in the slipping phase, viz. equations (3) and (5). This property complicates describing the system mathematically, which will also reflect in the computer model implementation. In this section three possible forms are presented. A fourth method views a drivetrain with clutch(es) as Linear Complementarity Problem (LCP), e.g. see [8]. 


\section{A. Lagrange using reduced matrices}

To incorporate the two phases of slip and stick into one model the equations of motion can be manipulated using reduced matrices. As stated by Verhagen [4], the equations (2.10) to (2.14) are written in matrix form, from which this differential equations results for the slipping phase, $\left(\mid \omega_{\mathrm{e}}-\right.$ $\left.\omega_{c} \mid>0\right)$ :

$$
M \underline{\ddot{q}}+D \underline{\dot{q}}+K \underline{q}=\underline{h} T_{c l}+\underline{e}_{1} T_{e}-\underline{e}_{5} T_{l}
$$

With the generalized displacement column $q=$ $\left[\begin{array}{lllll}\varphi_{\mathrm{e}} & \varphi_{\mathrm{c}} & \varphi_{\mathrm{t}} & \varphi_{\mathrm{w}} & \varphi_{\mathrm{v}}\end{array}\right]^{T}$. Herein $\underline{e}_{j}$ represents the $\mathrm{j}^{\text {th }}$ unit vector: $\underline{e}_{1}=\left[\begin{array}{lllll}1 & 0 & 0 & 0 & 0\end{array}\right]^{T}$. These unit vectors are used to insert the external torques into the model. The clutch torque is applied by the vector $\underline{\mathrm{h}}$ :

$$
\underline{h}=\underline{e}_{2}-\underline{e}_{1}=\left[\begin{array}{lllll}
-1 & 1 & 0 & 0 & 0
\end{array}\right]^{T}
$$

When the clutch is engaged the degrees of freedom of the system are reduced, as $\varphi_{\mathrm{e}}$ and $\varphi_{\mathrm{c}}$ are now equal. This is can be denoted by:

$$
\omega_{\mathrm{e}}-\omega_{\mathrm{c}}=-\underline{h}^{T} \underline{\dot{q}}=0
$$

This represents a kinematic constraint. A vector $\dot{q}_{r}$ with four instead of five components is introduced to take into account that $\varphi_{c}$ is no longer a degree of freedom. The original displacement column is multiplied with the reduction matrix $R_{r}$ to obtain the reduced displacement vector.

$$
\underline{\dot{q}}(t)=R_{r} \underline{\dot{q}}_{r}(t) ; \quad R_{r}^{T} \underline{h}=\underline{0}
$$

The clutch is set to close at time $t_{r}$, which implies $\underline{h}^{T} \underline{\dot{q}}\left(t_{r}\right)=0$ and $\underline{\dot{q}}\left(t_{r}\right)=R_{r} \underline{\dot{q}}_{r}\left(t_{r}\right)$. Let a matrix $Q_{r}$ satisfy the condition:

$$
Q_{r}^{T} R_{r}=I
$$

then

$$
\underline{\dot{q}}_{r}\left(t_{r}\right)=Q_{r}^{T} \dot{\dot{q}}\left(t_{r}\right)
$$

To determine $\underline{q}$ for $t>t_{r}, \underline{\dot{q}}$ is integrated. As the condition for stick is formulated in terms of velocity, an integration constant $\underline{\gamma}_{r}$ will appear in the position $\underline{q}(t)$.

$$
\begin{array}{r}
\underline{q}(t)=R_{r} \underline{q}_{r}(t)+\underline{\gamma}_{r} \\
\underline{\gamma}_{r}=\underline{q}\left(t_{r}\right)-R_{r} \underline{q}_{r}\left(t_{r}\right)
\end{array}
$$

If we take $\underline{q}_{r}\left(t_{r}\right)$ to be:

$$
\underline{q}_{r}\left(t_{r}\right)=Q_{r}^{T} \underline{q}\left(t_{r}\right)
$$

then

$$
\underline{\gamma}_{r}=\left[I-R_{r} Q_{r}^{T}\right] \underline{q}\left(t_{r}\right)
$$

Substituting $q_{r}$ into equation (2.12) and

$$
M R_{r} \underline{\ddot{q}}_{r}+D R_{r} \underline{\dot{q}}_{r}+K R_{r} \underline{q}_{r}=\underline{h} T_{c l}+\underline{e}_{1} T_{e}-\underline{e}_{4} T_{l}-K \gamma_{r}
$$

Pre-multiplication with $R_{r}^{T},\left(R_{r}^{T} \underline{h}=0\right)$ yields the equation:

$R_{r}^{T} M R_{r} \underline{q}_{r}+R_{r}^{T} D R_{r} \underline{\dot{q}}_{r}+R_{r}^{T} K R_{r} \underline{q}_{r}=R_{r}^{T} \underline{e}_{1} T_{e}-R_{r}^{T} \underline{e}_{4} T_{l}-R_{r}^{T} K \gamma_{r}$
The matrices $R_{r}$ and $Q_{r}$ are found by making sure they reduce the displacement column correctly. And $Q_{r}$ and $R_{r}$ should satisfy the conditions mentioned above in equations (2.18) and (2.19). In the actual case these matrices become:

$$
R_{r}=\left(\begin{array}{cccc}
1 & 0 & 0 & 0 \\
1 & 0 & 0 & 0 \\
0 & 1 & 0 & 0 \\
0 & 0 & 1 & 0 \\
0 & 0 & 0 & 1
\end{array}\right) \quad Q_{r}=\left(\begin{array}{cccc}
1 & 0 & 0 & 0 \\
0 & 0 & 0 & 0 \\
0 & 1 & 0 & 0 \\
0 & 0 & 1 & 0 \\
0 & 0 & 0 & 1
\end{array}\right)
$$

The model obtained here transforms the slipping equations into the sticking system through matrix multiplications. This results in an actual reduction in the order of the model. In essence this is correct, as the actual system indeed looses a degree of freedom, however it makes implementation overhead in a simulation model less compact. For other linear systems with many alternating degrees of freedom above method may be more useful.

\section{B. State space formulation}

The system can also be written in the piece-wise LTI state space form $\dot{x}=A x+B u$, as described in [5]. The state vector $x$ is defined in terms of the generalized coordinates, and the (control)inputs $u$ for the system are the engine torque $T_{\mathrm{e}}$ and the clutch torque $T_{\mathrm{c}}$ :

$$
x=\left[\begin{array}{lllllll}
\omega_{\mathrm{e}} & \omega_{\mathrm{c}} & T_{\mathrm{d}} & \omega_{\mathrm{t}} & T_{\mathrm{s}} & \omega_{\mathrm{w}} & v_{\mathrm{v}}
\end{array}\right]^{\mathrm{T}} \quad u=\left[\begin{array}{ll}
T_{\mathrm{e}} & T_{\mathrm{c}}
\end{array}\right]
$$

Writing the system in the state-space form allows for a model with switching parameter $\delta$ with $\delta=1$ if $\omega_{\mathrm{e}}-\omega_{\mathrm{c}} \neq 0$ and $\delta=0$ if the slipping speed becomes zero, i.e.

$$
\dot{x}=\delta\left(A_{\mathrm{sl}} x+B_{\mathrm{sl}} u\right)+(1-\delta)\left(A_{\mathrm{st}} x+B_{\mathrm{st}} u\right)+f(t)
$$

The matrices $A_{\mathrm{sl}}$ and $B_{\mathrm{sl}}$ represents the system when the clutch is slipping, whereas $A_{\text {st }}$ and $B_{\text {st }}$ are the system matrices for the sticking system. The column $f(t)$ contains the load torques due to air friction, rolling resistance and hill grade. The system matrices can be readily derived from the equations of motion given in Section II. The model adequately describes the system in state space form. A disadvantage of the piece-wise LTI formulation (30) is that the integration of the state $x$ demands twice as much computations, since both piece wise LTI systems are computed every time step. It depends on the slipping or sticking flag $\delta$, which of the two results are adopted in the state space column. The third formulation of the system model does not have this drawback and will be discussed next.

\section{The Karnopp approach}

The previous two formulations described two systems within one mathematical description. The sticking and slipping system however can also be described within one expression according to Karnopp, [6]. The main idea is to use the system equations (3) and (5) also for the sticking phase. In other words, there is no switching in the system 
description when actually moving from the sticking to slipping phase and vice versa. This approach was also used in [7] to model a torque converter lockup clutch.

In cases when the clutch is slipping the torque $T_{\mathrm{c}}$ can be manipulated by the actuator force $F_{\mathrm{n}}$ as was described by equation (7). However, when the clutch sticks the torque through the clutch can not be altered by the actuator. Instead, only the maximally transmittable torque $T_{\mathrm{c}}^{\max }$ can be changed as described by equation (9). Hence, if the equations (3) and (5) during the sticking phase are solved then first we have to compute the clutch torque $T_{\mathrm{c}}$ by contemplating that $\omega_{\mathrm{c}}=\omega_{\mathrm{e}}$, thus $\dot{\omega}_{\mathrm{c}}=\dot{\omega}_{\mathrm{e}}$. If we use this equality to compare equation (3) with (5), then the clutch torque during sticking can be readily found:

$$
T_{\mathrm{c}}=\frac{J_{\mathrm{e}}\left(T_{\mathrm{d}}+b_{\mathrm{c}} \omega_{\mathrm{c}}\right)+J_{\mathrm{c}} T_{\mathrm{e}}}{J_{\mathrm{c}}+J_{\mathrm{e}}}
$$

Consequently, when the clutch sticks, the torque $T_{\mathrm{c}}$ abruptly changes from the torque as a result of the actuator force $F_{\mathrm{n}}$ to the torque in the sticking case, i.e. as in equation (31). The criterion at which the clutch is assumed to be sticking may be formulated as $\omega_{\mathrm{e}}-\omega_{\mathrm{c}} \leq \varepsilon$. The advantage in using this formulation is that the same set of equations is used both for slipping and the sticking phases. Consequently, there is no switching required within this set, only a change of the external input variable $T_{\mathrm{c}}$. During sticking this variable becomes a constrained (according to (31)) rather then a controlled input (according to(7)).

We will use the Karnopp approach for the computer model implementation used throughout the remainder of this paper.

\section{CONTRol Design}

In this chapter a controller for clutch engagement will be designed, relying on the clutch model presented in the previous chapter. The difficulty in designing a controller for this system lies in the loss of controllability after the clutch engagement. We follow the decoupling control design proposed in [5]. Our contribution is a further analysis of the controller structure and a modification of into a more effective structure for controlling the drive comfort.

\section{A. Requirements of the controller}

To guarantee successful clutch engagement, two conditions have to be satisfied. The first one is the no-kill condition which states that the engine speed must remain above a minimal value, i.e. $\omega_{\mathrm{e}} \geq \omega_{\mathrm{e}}^{\mathrm{min}}$. The second one is the so called no-lurch condition which assumes that the derivative of the slip speed $\dot{\omega}_{\mathrm{sl}}=\dot{\omega}_{\mathrm{e}}-\dot{\omega}_{\mathrm{c}}$ at the moment of full engagement is close to zero.

These requirements however are in conflict with a fast engagement of the clutch. If we want to engage the clutch within a limited amount of time, we need to apply an amount of torque that could cause a high deceleration of the clutch disk $\dot{\omega}_{\mathrm{c}}$ that induces unwanted oscillations in the drivetrain. Also a overly fast engagement could cause an engine stall. A compromise between the different requirements and the desired engagement time has to be made.

\section{B. Decoupling controller}

The control inputs are chosen as in (29). For deriving the decoupling controller we assume a simplified powertrain model were all stiffnesses are infinite and internal damping is zero (except $b_{\mathrm{w}}$ ). In the Laplace domain, the control model can then be written as:

$$
\left[\begin{array}{c}
\omega_{\mathrm{e}} \\
\omega_{\mathrm{sl}}
\end{array}\right]=\frac{1}{s J_{\mathrm{e}}}\left[\begin{array}{cc}
1 & -1 \\
1 & -\left(1+s J_{\mathrm{e}} G(s)\right)
\end{array}\right] \cdot\left[\begin{array}{c}
T_{\mathrm{e}} \\
T_{\mathrm{c}}
\end{array}\right]+\left[\begin{array}{c}
0 \\
F(s)
\end{array}\right],
$$

where

$G(s)=\frac{s J_{\mathrm{v}}+b_{\mathrm{w}}}{\left(s J_{\mathrm{d}}+r^{2} b_{\mathrm{w}}\right)\left(s J_{\mathrm{v}}+b_{\mathrm{w}}\right)-b_{\mathrm{w}}^{2} r^{2}} ; J_{\mathrm{d}}=J_{\mathrm{c}}+J_{\mathrm{t}}+J_{\mathrm{w}} r^{2}$

By choosing the new input variables $v_{\mathrm{e}}$ and $v_{\mathrm{sl}}$ the two speeds can be decoupled and controlled separately. The transformation from the original to the new control variables becomes:

$$
\left[\begin{array}{l}
T_{\mathrm{e}} \\
T_{\mathrm{c}}
\end{array}\right]=\left[\begin{array}{cc}
1+s J_{\mathrm{e}} G(s) & 1 \\
1 & 1
\end{array}\right] \cdot\left[\begin{array}{c}
v_{\mathrm{e}} \\
v_{\mathrm{sl}}
\end{array}\right]
$$

The decoupled control system yields:

$$
\left[\begin{array}{c}
\omega_{\mathrm{e}} \\
\omega_{\mathrm{sl}}
\end{array}\right]=\left[\begin{array}{cc}
G(s) & 0 \\
0 & -G(s)
\end{array}\right] \cdot\left[\begin{array}{c}
v_{\mathrm{e}} \\
v_{\mathrm{sl}}
\end{array}\right]+\left[\begin{array}{c}
0 \\
F(s)
\end{array}\right]
$$

In this control system, $v_{\mathrm{e}}$ can be regarded as an engine speed controller, whereas $v_{\mathrm{sl}}$ then becomes the slip speed controller. Here, we choose $v_{\mathrm{e}}$ and $v_{\mathrm{sl}}$ to be PI controllers. They respectively control errors upon generations of smooth signals for the engine speed (ramp) and slip speed (exponential decay).

In Fig 3 and 4 the simulation results for open loop commands for $F_{\mathrm{n}}$ and $T_{\mathrm{e}}$ and for the decoupling controller (34)

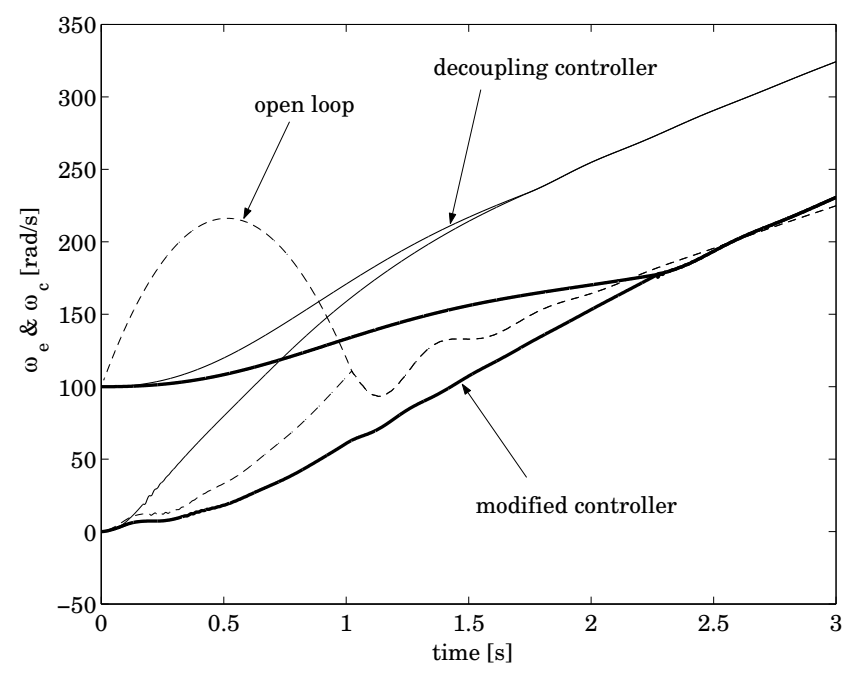

Fig. 3. Engine and clutch disc speed 
are presented. The 'modified controller' will be discussed in the next paragraph.

From the simulation results it can be seen that the decoupling controller achieves smoother engagement of the clutch, where the time derivatives of $\omega_{\mathrm{e}}$ and $\omega_{\mathrm{c}}$ are almost equal $\left(\dot{\omega}_{\mathrm{sl}} \approx 0\right)$ at the moment of engagement. Furthermore, the oscillation in the drive torque $T_{\mathrm{s}}$ after engagement of the open loop commanded clutch does hardly occur for the closed loop case. A disadvantage is the longer slipping time interval of the closed loop system. A disadvantage of both systems is the high initial drive torque $T_{\mathrm{s}}$ followed by a relative low value after the engagement. In terms of 'launch feel' this is generally not appreciable. The modified controller of the next paragraph circumvents this unpleasant behavior.

\section{Modified controller}

The equations in the decoupling control law (34) may also be written as

$$
T_{\mathrm{e}}(s)=T_{\mathrm{c}}(s)+\tau_{\mathrm{e}}(s)
$$

where $\tau_{\mathrm{e}}(s)=s J_{\mathrm{e}} G(s) \nu_{\mathrm{e}}(s)$. Since we want to influence the drive torque $T_{\mathrm{s}}$ more directly, we prefer to constraint rather than control the torque $T_{\mathrm{c}}$ during the slipping phase.

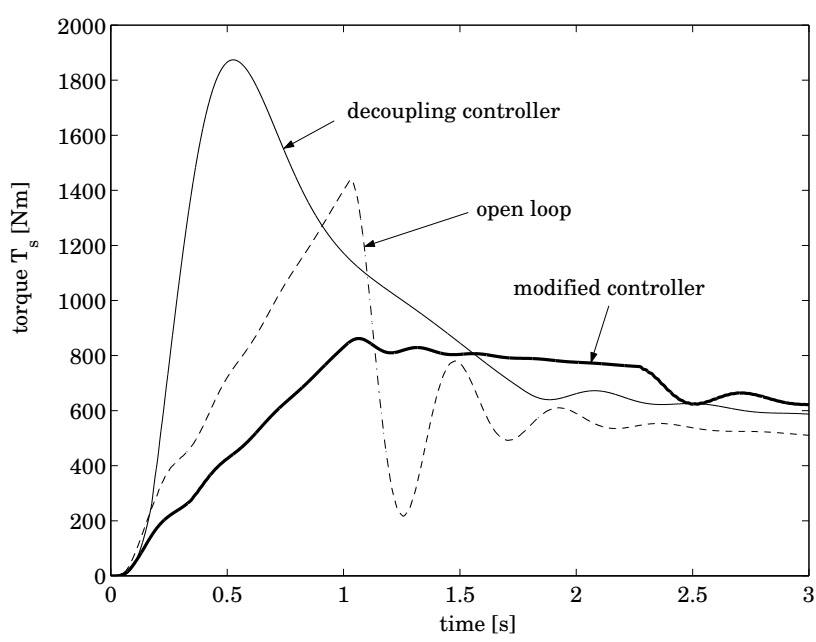

Fig. 4. Wheel torques

In combination with a more sophisticated tire model this introduces potentials for refined launch traction control, e.g. for icy road conditions. According to (36) we should then apply the same torque for $T_{\mathrm{e}}$ added by an additional control term $\tau_{\mathrm{e}}$. We used the original form $\tau_{\mathrm{e}}(s)=s J_{\mathrm{e}} G(s) v_{\mathrm{e}}(s)$, although it may be replaced by any (better performing) control design. The clutch torque is chosen to ramp up during $1 \mathrm{sec}$ and then remain constant. In Fig. 4 the result for the wheel torque can be seen. Due to accelerating powertrain inertias and losses, the torque at the wheels can not remain constant after the ramp. Furthermore, a minor drop in wheel torque occurs after engagement of the clutch. This is caused by the engine sided inertias which are now accelerated at a higher rate then during the slipping phase. Furthermore, the slipping phase takes somewhat longer. This may be further optimized by designing and tuning other controllers for $\tau_{\mathrm{e}}(s)$. For example using optimal control earlier proposed in [8]. Finally, the controller should be robust for unknown phenomena in the clutch friction coefficient, [9]. This is left for future research.

\section{CONCLUSIONS}

In this paper we considered three modelling techniques for a 7th order automotive powertrain system with dry launch clutch. The preferred model is based on the Karnopp approach, enabling an identical system description during slipping and sticking phase of the clutch. Furthermore, we adopted a decoupling controller from literature and compared the closed and open loop results with the proposed simulation model. A modified controller is proposed and analyzed that improves the controllability over the vehicle's drive comfort. Future work should focus on improving this modified controller and conducting experimental work for further evaluation of the controlled clutch system in various circumstances.

\section{ACKNOWLEDGMENTS}

The authors gratefully acknowledge the Master Track of Automotive Engineering Science (AES) at the Eindhoven University of Technology for supporting this research.

\section{REFERENCES}

[1] D. Cho and J.K. Hedrick, Automotive powertrain modelling for control, J. Dyn. Syst., Meas. and Control, vol. 111, 1989, pp 568-576.

[2] B.K. Powell, K.E. Bailey and S.R. Ckanek, Dynamic Modeling and Control of Hybrid Electric Vehicle Powertrain Systems, IEEE Control Systems Mag., vol. 18, no. 5, pp 17-33, 1998.

[3] R. Zanasi, A. Visconti, G. Sandoni and R. Morselli, "Dynamic Modeling and Control of a Car Transmission System", in 2001 IEEE/ASME International Conference on Advanced Intelligent Mechatronics, Como, Italy, 2001, pp. 416-421.

[4] T.C.P. Verhagen, Stop-Go with the ZI-powertrain: a first glance, internal report WFW2000.27, Technische Universiteit Eindhoven, 2000.

[5] F. Garofalo, L. Glielmo, L. Iannelli, and F. Vasca, "Smooth Engagement for Automotive Dry Clutch", in proc. 40th IEEE Conf. Decision and Control, Orlando, Dec. 2001, pp.529-534.

[6] D.C. Karnopp, D.L. Margolis, R.C. Rosenberg, System Dynamics: A Unified Approach, Wiley-Interscience, New York; 1990.

[7] A.F.A. Serrarens, Coordinated Control of the Zero Inertia Powertrain, $\mathrm{PhD}$ thesis Technische Universiteit Eindhoven, 2001.

[8] A. Haj-Fraj, F. Pfeiffer, Optimal Control of Gear Shift Operations in Automatic Transmissions, Jrnl. of the Franklin Institute, vol. 338, pp 371-390, 2001.

[9] D. Centea, H. Rahnejat, M.T. Menday, The Influence of the Interface Coefficient of Friction upon the Propensity to Judder in Automotive Clutches, Proc. Instn. Mech. Eng, vol. 213, no. 3, pp 245-258, 1999.

\section{APPENDIX: MODEL PARAMETERS}

\begin{tabular}{|c|l||c|l||c|l|}
\hline$J_{\mathrm{e}}$ & $0.13\left(\mathrm{kgm}^{2}\right)$ & $b_{\mathrm{c}}$ & $0.5(\mathrm{Nms} / \mathrm{rad})$ & $T_{\mathrm{r}}$ & $50(\mathrm{~N})$ \\
\hline$J_{\mathrm{c}}$ & $0.03\left(\mathrm{kgm}^{2}\right)$ & $b_{\mathrm{t}}$ & $0.05(\mathrm{Nms} / \mathrm{rad})$ & $\alpha$ & $0.65(-)$ \\
\hline$J_{\mathrm{t}}$ & $0.02\left(\mathrm{kgm}^{2}\right)$ & $r_{\mathrm{t}}$ & $0.2538(-)$ & $R_{\mathrm{W}}$ & $0.31(\mathrm{~m})$ \\
\hline$J_{\mathrm{w}}$ & $1.70\left(\mathrm{kgm}^{2}\right)$ & $r_{\mathrm{f}}$ & $0.2681(-)$ & $\rho$ & $1.25\left(\mathrm{~kg} / \mathrm{m}^{3}\right)$ \\
\hline$J_{\mathrm{v}}$ & $115\left(\mathrm{kgm}^{2}\right)$ & $k_{\mathrm{S}}$ & $6000(\mathrm{Nm} / \mathrm{rad})$ & $A$ & $2.01\left(\mathrm{~m}^{2}\right)$ \\
\hline$k\left(\varphi_{\mathrm{d}}\right)$ & eqn. $(4)$ & $b_{\mathrm{W}}$ & 930 & $c_{\mathrm{d}}$ & $0.32(-)$ \\
\hline
\end{tabular}

